\title{
A Não-Escola: \\ Os Sentidos Atribuídos à Escola e ao Professor Hospitalares por Pacientes Oncológicos
}
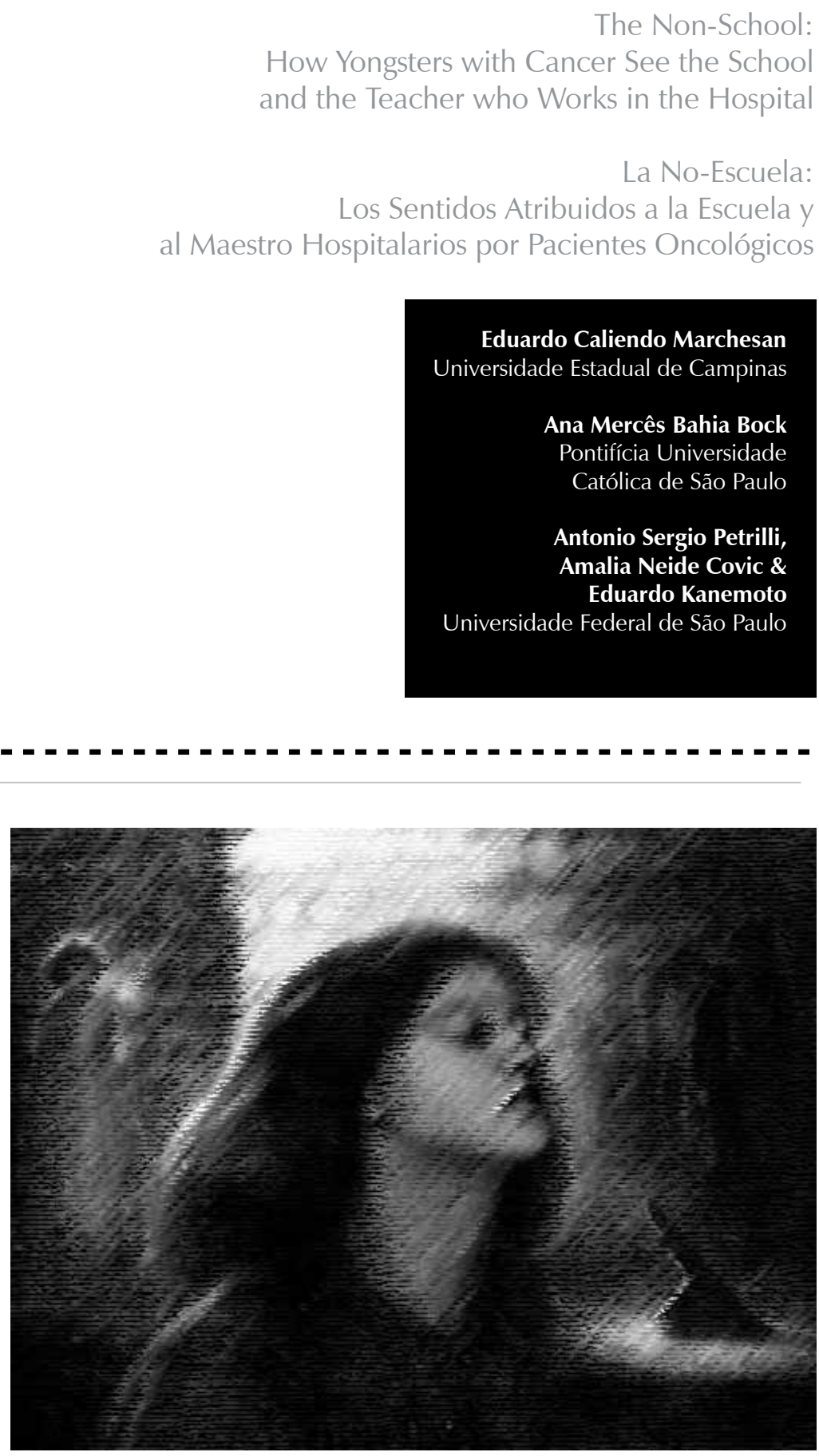
Resumo: Este estudo busca compreender a dimensão subjetiva de pacientes oncológicos que estudam ou estudaram na escola hospitalar do IOP-GRAACC-UNIFESP. Através de uma metodologia qualitativa baseada na Psicologia sociohistórica, há o objetivo de apreender os sentidos atribuídos pelos sujeitos estudados à escola hospitalar, ao professor hospitalar e à aprendizagem que ocorre nesse contexto. Foi possível observar que a escola hospitalar é marcada pela ausência significativa dos elementos que compõem o sentido acerca da instituição escolar tradicional, ao mesmo tempo em que é vista como um espaço de aprendizagem considerado mais agradável. O professor é carregado de uma carga afetiva bastante positiva, e o saber por ele vinculado ganha aspectos diferenciados. A escola hospitalar deve se afirmar e pautar sua atuação nas suas diferenças, mesmo quando baseadas na ausência, assumindo-se, assim, como espaço escolar específico. Palavras-chave: Ensino. Hospitalização. Escolas. Câncer.

\begin{abstract}
This paper had the objetive of understandig the subjective dimension of the oncological patients who receive an educational provision at the IOP-GRAACC-UNIFESP. Using a qualitative methodology, based on the social-historical psychology, we intended to understand how these students see the hospital school, the teacher who works at the hospital and the kind of apprenticeship that is carried on in this context. We have noticed that the hospital school is marked by a significative absense of the elements that build the way the teenagers see the tradicional school, at the same time that it is seen as a more pleaseant learning environment. The teacher who works at the hospital is loaded with a positive affectivity charge and the subjects he teaches have other functions in this context. The hospital school must act according to its differences, even when they are based on something that is missing, assuming itself as a special scholar enviroment.
\end{abstract}

Keywords: Teaching. Hospitalization. Schools. Cancer.

Resumen: Éste estudio busca comprender la dimensión subjetiva de pacientes oncológicos que estudian o estudiaron en la escuela hospitalaria del IOP-GRAACC-UNIFESP. A través de una metodología cualitativa basada en la Psicología sociohistórica, tiene el objetivo de captar los sentidos atribuidos por los sujetos estudiados a la escuela ospitalaria, al profesor hospitalario y al aprendizaje que ocurre en ese contexto. Fue posible observar que la escuela hospitalaria es marcada por la ausencia significativa de los elementos que componen el sentido acerca de la institución escolar tradicional, al mismo tiempo en el que es vista como un espacio de aprendizaje considerado más agradable. El maestro está cargado de una carga afectiva bastante positiva, y el saber por él vinculado gana aspectos diferenciados. La escuela hospitalaria debe afirmarse y pautar su actuación en sus diferencias, incluso cuando son basadas en la ausencia, asumiéndose, así, como espacio escolar específico.

Palabras clave: Enseñanza. Hospitalización. Escuelas. Cáncer.

Quando Haroldo de Campos publica seu ensaio "Serafim: um Grande Não-livro" (Campos, 1980) acerca da obra Serafim Ponte Grande, do escritor Oswald de Andrade, ele se juntava a um grupo de pessoas que vinham retomando, tirando de um certo ostracismo, a produção desse autor. Campos se dirigia àquela obra singular, àquele livro, caracterizando-a como um não-livro. $\mathrm{O}$ que fazia com que o texto de Oswald, materializado, sim, na forma de um livro, pudesse ser identificado como a negação do objeto que, aparentemente, ele era? As características da obra, a maneira como ela transgredia as fronteiras entre os gêneros, seu caráter fragmentário e sua composição a partir de colagens desviavam o leitor da estrutura com a qual ele estava acostumado, faziam com que, a despeito do fato de ele ter nas mãos um objeto, o livro, houvesse um estranhamento no momento da leitura. Aquele não era um livro padrão, não trazia as características costumeiras dos romances brasileiros que o precederam. Produziase, então, no leitor, o seguinte efeito: ele reconhecia o livro ao mesmo tempo em que não via ali as marcas típicas dos livros. Havia uma especificidade, algo próprio àquela obra que a diferenciava, porém, também havia algo que a aproximava, que permitia um reconhecimento por parte do público leitor. O próprio Campos, ao afirmar que temos ali um não-livro, pressupõe, pela necessidade da afirmação, que outros poderiam enxergar Serafim como um livro.

O título da pesquisa que aqui é apresentada, ao definir a escola hospitalar como uma 
não-escola, se aproxima das idéias descritas acima. Procuramos mostrar que a escola no hospital é uma não-escola, porque ela está despida de elementos fundamentais que garantem o fato de a instituição escolar ser vista como tal pelos alunos-pacientes (amigos, um ambiente físico próprio e o recreio, dentre outros). Ao mesmo tempo, ela carrega especificidades quanto à sua atuação e se afirma enquanto espaço escolar através da ação do professor hospitalar, do vínculo com a escola de origem do aluno e pelo papel representado pelo saber. À maneira do livro que é e não é livro, a escola hospitalar possui particularidades que a afastam da escola de origem ao mesmo tempo em que afirmam o seu caráter de espaço escolar.

Apesar de atrair um interesse crescente, a produção científica acerca da educação hospitalar ainda é pequena. Trata-se de uma literatura que abarca trabalhos preocupados em validar experiências e traçar os objetivos de uma atuação escolar no hospital. No geral, tais produções são desenvolvidas a partir de um olhar pedagógico, com o objetivo de definir parâmetros e descrever o contexto da atuação escolar hospitalar (Ceccim, 1999; Ceccim \& Fonseca, 1999; Fonseca, 1999b, 2000, 2003; Paula, 2004), mostrar o cenário atual dessa modalidade educacional (Fonseca, 1999a, 2001), discutir a formação de educadores (Covic, 2003) ou descrever algumas experiências que vêm ocorrendo. No que diz respeito ao olhar da Psicologia para esse tipo de atuação, vemos que ele é pequeno. Podemos nos reportar ao estudo de Medeiros e Gabardo (2004), que busca discutir alguns aspectos da relação professoraluno nas classes hospitalares a partir de uma perspectiva comportamental, como um exemplo. Porém, trabalhos sobre esse contexto escolar fundados em uma psicologia de base materialista, histórica e dialética, tal como o que realizamos, são inexistentes.

O objetivo aqui foi o de promover uma discussão acerca do papel da educação dentro do hospital a partir da visão do próprio aluno, buscando apreender a dimensão subjetiva da experiência da educação de pacientes oncológicos em um ambiente hospitalar. Os temas professor, escola e aprendizagem foram escolhidos como alvos da pesquisa na medida em que, na hipótese levantada, são aqueles que compõem o significado de escola socialmente partilhado. Além disso, dado o fato de que os alunospacientes chegavam ao hospital carregando uma grande experiência de contato com a escola de origem e seu professor, era também importante que procurássemos conhecer os sentidos atribuídos pelos sujeitos a essas figuras.

Dessa forma, buscamos nos aproximar dos sentidos que os alunos-pacientes do IOPGRAACC-UNIFESP atribuíam à escola de origem, à escola hospitalar, ao professor da escola de origem, ao professor da escola hospitalar, à aprendizagem na escola de origem e à aprendizagem na escola hospitalar. A partir disso, foi possível produzir maior visibilidade da dimensão subjetiva da experiência vivida por tais jovens.

Para a realização dos objetivos propostos, recorremos a autores da Psicologia sociohistórica, valendo-nos especialmente das categorias sentido e significado, trazidas por Vigotski e retomadas por GonzálezRey. Entrevistamos, então, alunos da escola hospitalar, e, a partir de seus discursos, construímos as zonas de sentido sobre escola, professor e aprendizagem, tanto em relação à escola de origem quanto ao ambiente hospitalar, a partir de metodologia apresentada por Aguiar e Ozella (2006). A articulação dos dados produzidos por uma bibliografia que abarcou temas considerados relevantes permitiu-nos produzir teorizações acerca da experiência subjetiva do paciente com câncer que estuda no hospital, entendendo-o como um ser histórico, marcado pelas determinações sociais que se estabelecem 
e que é, ao mesmo tempo, capaz de atuar sobre o mundo, modificando-o.

A bibliografia a que nos referimos envolveu a história da instituição escolar no Brasil, mostrando as marcas que ela foi deixando na educação, o surgimento da idéia de educação especial e educação inclusiva, levando em conta como a educação hospitalar se insere nesse contexto, como diferentes autores vieram trabalhando a relação professor-aluno, a afetividade que envolve tal relação e um olhar para o sujeito com câncer, buscando compreender que aspectos marcam a sua experiência.

Acreditamos que o estudo da experiência da educação hospitalar na sua dimensão subjetiva, conhecendo os sentidos que o sujeito constrói, seja algo importante, na medida em que dá voz àquele que é o alvo desse tipo de atuação: o aluno-paciente. Compreender como esses sujeitos configuram subjetivamente a imagem da escola hospitalar e de seu professor garante a possibilidade da realização de um trabalho que esteja alinhado às necessidades desses indivíduos. Isso cria um vocabulário básico para a compreensão de como os alunos-pacientes vivem a experiência educacional no hospital, contribuindo para o desenvolvimento de outros estudos sobre o tema e para a prática daqueles que trabalham nesse espaço.

\section{Projeto Escola-Móvel: Aluno Específico}

O projeto Escola Móvel: Aluno Específico acontece dentro do IOP-GRAACC-UNIFESP. O GRAACC ${ }^{1}$, Grupo de Apoio ao Adolescente e à Criança com Câncer, fundado em 1991, é uma instituição sem fins lucrativos, que se mantém à base de repasses realizados pelo SUS e por doações de empresas privadas e pessoas físicas. A grande maioria dos seus pacientes estuda em escolas municipais e estaduais, e as crianças que chegam à instituição são provenientes de diversas partes do Brasil. Existem também casos de pacientes estrangeiros, habitantes de outros países da América do Sul.

Por conta de particularidades do tratamento, muitas crianças e adolescentes com câncer acabam por interromper sua vida escolar ou faltam bastante à escola. O projeto Escola Móvel: Aluno Específico tem como objetivos impedir que o educando pare de estudar devido ao longo período de tratamento e garantir a manutenção do vínculo do alunopaciente com a sua escola e com o saber de maneira geral.

Para seu funcionamento, o projeto conta com uma equipe formada por dois coordenadores, cinco professores e voluntários. Ao contrário do que ocorre em outros espaços de educação no hospital, os professores do projeto Escola Móvel não são professores da rede pública de ensino, mas sim, estagiários que cursam a faculdade de Letras, Física e Matemática, dentre outras. Esses docentes recebem um acompanhamento diário de suas atividades, fornecido pelos coordenadores do projeto.

A maioria dos alunos-pacientes freqüenta o hospital em regime de hospital-dia. Registrados no banco de dados da Escola Móvel estão mais de 1200 alunos, cuja freqüência pode ser diária ou até de uma vez a cada seis meses.

Os professores atendem os alunos individualmente, em aulas de duração variável. As aulas ocorrem em todo o hospital, e têm como público-alvo alunos que vão do primeiro ano do ensino fundamental até o terceiro do ensino médio. Nem sempre os professores sabem quais alunos estarão presentes devido às dificuldades relativas à própria rotina do hospital.

Uma equipe de voluntários é responsável pelo controle de freqüência que ocorre 
O significado da palavra... é uma unidade indecomponível de ambos os processos, e não podemos dizer que ele seja um fenômeno da linguagem ou um fenômeno do pensamento...

Vigotski (2000) diariamente. Esses mesmos voluntários entram em contato com as escolas dos alunos com o objetivo de informá-las a respeito da situação de cada criança/adolescente e solicitar o programa de estudos utilizado em sala. Quando é de fato enviado, esse programa é seguido com o aluno-paciente, ainda que, muitas vezes, acabe por ser adaptado às necessidades decorrentes da situação específica por ele vivida.

As aulas ministradas são registradas no banco de dados da escola e arquivadas em uma pasta individual do aluno-paciente. Ao final de um período de alguns meses, o material trabalhado é enviado à escola de origem acompanhado de um relatório de aproveitamento. O material do alunopaciente somado ao relatório serve como documento que comprova as atividades no hospital e garante, muitas vezes, a aprovação do estudante na série que cursa.

\section{Metodologia}

Trabalhando a partir do referencial teórico da Psicologia sociohistórica, buscamos apreender os sentidos atribuídos por jovens pacientes oncológicos que realizaram parte de sua escolarização no ambiente hospitalar à escola hospitalar, ao professor que atua nesse espaço e ao aprendizado que aí ocorre. Procuramos também apreender os sentidos atribuídos a esses mesmos temas em relação à escola de origem dos alunos-pacientes. Para tanto, partimos do discurso de cada um dos sujeitos trabalhados, utilizando tal discurso como material de análise para nos aproximarmos das produções subjetivas dos jovens.

De acordo com Vigotski (2000), o significado da palavra é a unidade fundamental que nos mostra, em sua forma mais simples, a indissociabilidade entre o pensamento e a linguagem. Ele nos diz:
O significado da palavra... é uma unidade indecomponível de ambos os processos, e não podemos dizer que ele seja um fenômeno da linguagem ou um fenômeno do pensamento... Assim, o significado da palavra é, ao mesmo tempo, um fenômeno de discurso e intelectual... é um fenômeno do pensamento discursivo ou da palavra consciente, é a unidade da palavra com o pensamento. (p. 398)

As significações construídas ao longo da história da humanidade estão materializadas na linguagem, e, portanto, apropriandose desta, o homem está entrando em contato com as significações historicamente produzidas. No que se refere à significação da palavra tomada de uma forma particular pelo indivíduo, Vigotski (2000) propõe a categoria que chama de sentido. A esse respeito, o autor diz:

\footnotetext{
o sentido de uma palavra é a soma de todos os fatos psicológicos que ela desperta em nossa consciência. Assim, o sentido é sempre uma formação dinâmica, fluida, complexa, que tem várias zonas de estabilidade variada. O significado é apenas uma dessas zonas do sentido que a palavra adquire no contexto de algum discurso e, ademais, uma zona mais estável, uniforme e exata.... Tomada isoladamente no léxico, a palavra tem apenas um significado. Mas este não é mais que uma potência que se realiza no discurso vivo, no qual o significado é apenas uma pedra no edifício do sentido. (p. 465)
}

A apreensão dos sentidos produzidos pelos diversos sujeitos não é plena e absoluta, já que o acesso que temos ao real nunca é integral, mas sempre parcial, limitado por nossas práticas. O conhecimento é uma construção humana, e não algo previamente dado esperando para ser descoberto. A partir dessas idéias, surgiu o conceito de zona de sentido, que funciona como um recurso metodológico valioso. González Rey (2005) define zona de sentido como "aqueles espaços de inteligibilidade que se produzem na pesquisa científica e não esgotam a questão que significam, senão que, pelo 
contrário, abrem a possibilidade de seguir aprofundando um campo de construção teórica" (p. 6). Dessa maneira, fica para trás a idéia de um conhecimento que possui uma relação linear com a realidade, o que de fato era uma visão reducionista e arbitrária a respeito desta por não considerá-la em sua complexidade. Esse recurso metodológico permite que se ouça o sujeito e se sistematize o discurso, construindo zonas de sentido sobre a temática estudada.

Nesta pesquisa, buscou-se produzir zonas de sentido a respeito dos seis temas já mencionados. Para tanto, 28 sujeitos (número sugerido pelo Departamento de Pediatria da UNIFESP-EPM, ao qual a pesquisa estava ligada) foram selecionados, respeitandose os seguintes critérios: serem pacientes em tratamento ou fora de tratamento do IOP-GRAACC-UNIFESP, serem ou terem sido alunos-pacientes do projeto Escola Móvel: Aluno Específico, terem realizado sua escolarização na rede pública de ensino, estarem cursando o ensino médio ou já têlo concluído. Foram escolhidos os alunos pertencentes ao ensino médio para que fosse possível lidar com adolescentes ou adultos jovens, trabalhando apenas com a produção oral dos sujeitos durante as entrevistas e abrindo mão das possíveis atividades lúdicas que a pesquisa com crianças poderia exigir. Para evitar um corte plenamente arbitrário no que diz respeito à idade dos sujeitos, optamos por utilizar a divisão feita pela própria instituição escolar entre ensino fundamental e ensino médio na hora de definir os participantes da pesquisa. Quanto ao fato de trabalharmos apenas com alunos da escola pública, isso se deu porque tais estudantes representam a grande maioria de alunos-pacientes atendidos no IOPGRAACC-UNIFESP.

Dessa forma, participaram da pesquisa 17 sujeitos do sexo masculino e 11 do sexo feminino; 4 desses sujeitos pertenciam ao primeiro ano do ensino médio, 9 ao segundo, 5 ao terceiro e 10 já haviam completado o ensino médio, sendo que, no geral, suas idades variavam dos 16 até os 24 anos; 17 sujeitos habitavam o Estado de São Paulo, sendo 8 da capital e 9 de outras cidades, e 11 eram de outros Estados do Brasil, sendo 5 de suas respectivas capitais e 6 de outras cidades. No que diz respeito à produção dos dados, concordamos com Ozella (2003), que destaca a necessidade de instrumentos que provoquem a expressão do sujeito, permitindo que ele forneça ao pesquisador indicadores que viabilizem o processo construtivo/ interpretativo, necessário para a construção do conhecimento. Aqui, contamos com uma entrevista individual aberta dividida em três etapas. Em um primeiro momento, uma série de figuras que envolviam o professor, a escola, o hospital e diversos outros aspectos desses elementos foram apresentadas aos sujeitos. Quatro perguntas foram feitas: "O que você acha que seja a escola?", "O que você acha que seja a escola no hospital?", "O que você acha que seja o professor?", "O que você acha que seja o professor no hospital?" Os sujeitos deveriam, então, escolher o número de fotos que quisessem, respondendo cada uma das perguntas através das imagens. Em seguida, foi pedido a eles que explicassem o porquê da escolha daquelas figuras. Um roteiro formulado previamente trazia tópicos que complementavam a pesquisa e que eram considerados importantes pelo pesquisador. Após essa primeira etapa, duas folhas foram entregues aos participantes para que eles escrevessem as diferenças que viam entre a escola de origem e a escola hospitalar bem como as diferenças entre o professor da escola de origem e o professor hospitalar. Por fim, foi-lhes contada a seguinte história: um extraterrestre veio à Terra com o intuito de conhecer nosso planeta. Tendo se deparado com o sujeito entrevistado, pediu a ele que Ihe respondesse o que eram o professor e a escola de origem, e o professor e a escola hospitalares. A entrevista foi acompanhada 
por um questionário socioeconômico para a caracterização dos sujeitos.

A análise dos dados construídos buscava produzir núcleos de significação a respeito dos temas já mencionados. Esses núcleos de significação correspondem às principais questões abordadas pelo entrevistado ao longo de sua fala, e visam a criar uma visibilidade acerca dos sentidos produzidos pelos sujeitos. É importante dizer que não é apenas a freqüência com que uma questão aparece que garante a sua importância, mas sim, sua capacidade de gerar emoções, motivar e envolver o sujeito. Também é possível que um núcleo seja criado em torno de uma questão que não tenha sido tratada de forma tão marcante pelo entrevistado, mas que é considerada relevante pelo pesquisador que a enxerga a partir da teoria em que se baseia.

Para a formulação desses núcleos, há a seleção de trechos do discurso do sujeito que correspondem ao dado bruto, chamados de pré-indicadores. A reunião de préindicadores a partir de uma temática comum permite a formulação dos indicadores, etapa intermediária desse processo. A reunião dos indicadores somada a um salto interpretativo realizado pelo pesquisador garante a produção dos diversos núcleos de significado do sujeito. Aqui, os núcleos se organizaram dentro dos seis temas mencionados anteriormente. A formulação dos núcleos contou com o auxílio do programa SPAD-t, utilizado para a organização dos dados. Além disso, leituras flutuantes realizadas pelo pesquisador permitiram o levantamento de outros aspectos considerados importantes na formulação dos núcleos.

A partir daí, foram feitas as análises propriamente ditas. No momento da análise, é preciso apreender as determinações que constituem a forma como os sujeitos dão significado às questões levantadas. Para a realização desse objetivo, as questões reunidas nos núcleos foram relacionadas à história do indivíduo e aos dados colhidos no questionário socioeconômico. Além disso, as falas, os conteúdos e as emoções do sujeito, agrupadas nos núcleos, foram vistas a partir da inserção no processo histórico que as constituiu. Esse trabalho permite a compreensão do modo como o social é configurado pelo sujeito e transformado em algo subjetivo, através de um processo que é ao mesmo tempo histórico-social e individual. Tal procedimento permitiu o trabalho com as diversas zonas de sentido produzidas a respeito dos temas destacados. Conforme já mencionamos, as zonas de sentido funcionam como um recurso metodológico que nos permite uma aproximação com os sentidos subjetivos. Essa aproximação é necessária devido ao fato de os sentidos, dada a sua complexidade, não poderem ser plenamente apreendidos. Há a possibilidade de nos aproximarmos deles, mas não de defini-los na sua inteireza.

A análise foi feita com cada um dos sujeitos individualmente, pois concordamos com González Rey (2005), quando diz:

O sujeito é uma unidade essencial para os processos de construção na pesquisa qualitativa, pois a singularidade é a única via que estimula os processos de construção teórica portadores de um valor de generalização perante o estudo da subjetividade. A dimensão de sentido dos processos psíquicos requer chegar ao geral a partir da compreensão de processos e de formas de organização que apresentem características singulares de expressão. É o estudo da singularidade que nos permite acompanhar um modelo de valor heurístico para chegar a conclusões que estão além do singular e que são inexeqüíveis sem o estudo das diferenças que o caracterizam. (p. 113)

Após o trabalho individual com os sujeitos, foi feita uma síntese dos sentidos produzidos pelos alunos-pacientes a respeito de cada um dos temas trabalhados. Com isso, buscamos garantir a produção de visibilidade acerca 
dos aspectos gerais que marcavam a visão dos sujeitos a respeito da escola de origem, da escola hospitalar, do professor da escola de origem, do professor-hospitalar, da aprendizagem na escola de origem e da aprendizagem na escola hospitalar. São essas sínteses que constituem os resultados deste trabalho.

\section{Resultados}

Os resultados aqui apresentados são sínteses efetuadas acerca de cada um dos seis temas abordados neste trabalho. Tais sínteses foram construídas a partir dos sentidos atribuídos individualmente pelos sujeitos a esses temas, levando-se em conta a freqüência com que os sentidos apareciam entre os sujeitos e sua importância relativa, avaliada a partir da capacidade de esses sentidos produzirem contradições ou ambigüidades. Elas são, portanto, representativas do modo como a população trabalhada entende a escola de origem, a escola hospitalar, o saber nesses dois espaços educativos, o professor da escola de origem e o professor hospitalar.

À exceção do tema "Aprendizagem na escola hospitalar", após a apresentação da síntese para cada tema, há comentários interpretativos que preparam o caminho para a discussão final.

\section{Escola de origem}

A escola de origem é vista da seguinte maneira pelos sujeitos:

- Os sentidos produzidos pelos diversos sujeitos acerca da escola aparecem atravessados pelos problemas que caracterizam a educação pública brasileira em sua diversidade. Aparecem elementos de sentido relativos à sua degradação e à falta de recursos materiais;

- O espaço da escola, juntamente aos elementos que o constituem, constrói zonas de sentido acerca da escola, que passa a ser reconhecida enquanto tal a partir destes elementos: o giz, a lousa, a sala, o livro, o caderno e a quadra, que são marcantes e servem como caracterizadores da instituição escolar;

- A escola é entendida como um lugar no qual se deve aprender; no entanto, os amigos são possivelmente aquilo que marca de forma mais intensa os sentidos acerca da escola de origem;

- A bagunça é, no mais das vezes, dotada de um caráter positivo. Existem, é verdade, caracterizações da bagunça como algo prejudicial, mas elas convivem de forma ambivalente com o prazer que essa vivência proporciona;

- A escola é vista como um lugar "chato", do qual é necessário fugir, e o aluno atuará buscando escapar ao controle escolar. Devese ter respeito à escola, mas os alunos não a respeitam. Matar aula e "torcer" para o professor não aparecer são idéias e atitudes comuns;

- Quanto menos escola, melhor, desde que isso não leve o aluno a repetir de ano. A repetência é algo problemático, já que atrasa a vida do sujeito e o afasta dos colegas;

- A escola é vista como uma instituição que está distante da realidade do aluno, centrada na sala de aula e alheia ao mundo;

- A doença também atravessa a percepção acerca da escola de origem. Colegas aparecem como pessoas cujo olhar vem carregado por um preconceito, que caçoam das dificuldades dos sujeitos e das marcas deixadas pela doença.

Os sentidos produzidos acerca da escola de origem carregam valores ambíguos. Há aquilo que marca a vivência dos alunos de 
forma positiva e prazerosa, relativo ao contato com os colegas e com as vivências em grupo dentro e fora da classe, ao mesmo tempo em que há o reconhecimento da escola como o lugar de uma aprendizagem importante que, no entanto, é tida, no mais das vezes, como chata. Cortella (1998) já apontava essa relação dos jovens com a escola, marcada por um gosto pelos espaços de socialização e pelo encontro com os colegas, que contrasta com uma espécie de repúdio pelas aulas.

A ambigüidade também está presente no contato com os colegas. Ao mesmo tempo em que há essa vivência positiva relatada, os sujeitos sentem um olhar diferenciado dos outros estudantes em relação às marcas deixadas pela doença (muletas, falta de cabelo, etc.). Trabalhos como os de Bessa (2000), Pendley, Dahlquist e Dreyer (1997) e Woodgate (2005) falam da dificuldade vivida por adolescentes com câncer na hora de se haver com as marcas da doença, especialmente no que diz respeito à adaptação psicossocial aos diversos ambientes. Às dificuldades consideradas típicas da adolescência, esses sujeitos teriam somadas aquelas relativas à doença e ao seu tratamento.

Quanto ao conhecimento veiculado nessa instituição, ele é visto como distante da realidade do aluno. Essa distância é histórica na escola brasileira, e vem, como aponta Romanelli (1980), desde o ensino dos jesuítas. Entretanto, esse mesmo conhecimento é visto como o caminho para a garantia de um bom emprego para os jovens no futuro, de um retorno financeiro e de uma possibilidade de ascensão social (algo que não se comprova quando do término dos estudos).

\section{Escola hospitalar}

A escola hospitalar é vista da seguinte maneira:
- Tem a função de permitir que o alunopaciente prossiga seus estudos mesmo estando afastado da escola de origem;

- A escola hospitalar é tida como um lugar de "ajuda";

- Ela ganha sentido na medida em que está vinculada à escola de origem, trabalhando o programa de estudos enviado e funcionando ligado a ela;

- O conteúdo com o qual ela irá trabalhar será, na maioria das vezes, uma revisão daquilo que já foi estudado na escola de origem;

- Aparece a idéia de que a escola hospitalar acaba por servir de distração para o alunopaciente, entediado nos longos períodos de internação;

- Esse espaço escolar cumpre o papel de evitar que o sujeito pense apenas na sua doença e no tratamento;

- Ela não é obrigatória: é entendida como algo que funciona levando em consideração a necessidade e a disposição do aluno-paciente. O aluno-paciente influi no tempo da escola hospitalar, que passa a funcionar levando em consideração o tempo do próprio estudante;

- A participação do estudante também se estende às disciplinas que serão trabalhadas. Ele pode escolher que matérias quer cursar;

- A percepção que os sujeitos têm desse espaço revela que não existe um lugar específico para a escola no hospital: o espaço da escola se confunde com o espaço do hospital;

- Na escola hospitalar, há uma redução dos elementos que constroem o sentido atribuído à escola de origem. A escola no hospital aparece como um espaço carente de amigos. 
Ela é marcada pela ausência de coisas como a bagunça e as brigas, o que pode ser positivo, mas que acaba por evidenciar a falta dos colegas;

- A morte marca as relações que se estabelecem nesse espaço. O falecimento de colegas impressiona bastante os sujeitos, que acabam por ter de lidar com a possibilidade da ocorrência de suas próprias mortes. Produz-se uma relação ao mesmo tempo de afastamento e de aproximação com os colegas;

- A escola no hospital é o professor e sua aula: a ausência de um espaço específico, dos colegas, de bagunças e de brigas acaba por reduzir a escola hospitalar à figura do professor.

A escola hospitalar tem seu sentido construído na comparação com a escola de origem; a escola hospitalar aparece então marcada pela ausência de elementos que caracterizam os diversos sentidos a respeito da escola de origem, o que poderia fazer com que se entendesse que ela não é uma escola. Porém, o professor hospitalar e sua aula, carregando o conhecimento escolar e marcando um espaço educacional diferenciado, garantem o caráter escolar desse espaço.

Há um contraste que se estabelece na produção de sentidos acerca da escola hospitalar: é fundamental que ela esteja voltada para uma escolarização formal, na medida em que isso garanta ao alunopaciente a continuidade dos estudos e o impeça de repetir o ano. Ao mesmo tempo, há uma cobrança e uma obrigação menores, assim como um caráter de passatempo, de entretenimento, que esvazia seu papel de instituição de ensino.

\section{Professor da escola de origem}

É possível dividir os diversos professores que aparecem nos discursos em dois grupos: o bom professor e o professor ruim.

\section{Bom professor:}

- Representa a visão ideal acerca do que deveria ser a tarefa docente;

- Dá voz ao aluno;

- Busca fazer com que o aluno compreenda aquilo que está sendo explicado;

- É empenhado e interessado;

- Desenvolve seu trabalho por conta de um gosto próprio, de uma vontade de ajudar os alunos.

\section{Professor ruim:}

- Parece trabalhar tendo a experiência dos alunos como fator preponderante;

- Cumpre sua tarefa apenas por obrigação;

- É desinteressado em relação ao aluno;

- Não se preocupa verdadeiramente em ensinar e ajudar, há apenas o cumprimento das tarefas;

- É autoritário, "pega no pé" do aluno. No entanto, essa é uma idéia ambivalente, já que o "pegar no pé" pode, por vezes, ser entendido como uma forma de atenção do professor para com o aluno.

O que difere os dois tipos de professor caracterizados pelos sujeitos parece ser o olhar que eles dedicam aos alunos, olhar esse que vem atravessado por uma afetividade expressa no interesse e na dedicação mencionadas.

Apesar dessas definições acerca do bom e do mau professor, a tarefa docente primordial 
em qualquer que seja o caso é ensinar. Ele pode até ser despido das características valorizadas pelos sujeitos, desde que siga ensinando. O saber que o professor possui é aquele que vale dentro da classe. O aluno não sabe, enquanto o professor possui um conhecimento que deve ser transferido para os estudantes, fato que mostra como as idéias de Freire (1987), críticas de uma educação baseada na mera transferência de conhecimentos, seguem atuais e como a "educação bancária", por ele descrita, ainda está presente nas práticas escolares, constituindo parte da visão que o aluno tem acerca do professor.

No que diz respeito à relação entre o professor e o aluno, vemos que esta se limita à sala de aula. Esse fato muda apenas em situações extraordinárias, como a da doença, por exemplo, quando o professor passa a visitar o aluno e a se interessar por seu estado de saúde.

\section{Professor hospitalar}

\section{Papéis do professor hospitalar:}

- Motivar o aluno-paciente para o estudo e mostrar ao estudante que ele é capaz de estudar;

- Há a percepção de que o professor hospitalar produz na criança a idéia de que ela pode vir a se curar.

Características desse profissional:

- Bom humor e alegria;

- Todos têm o mesmo jeito, são professores "neutros", diferentemente do que ocorre na escola de origem, na qual os professores são diferentes, podendo ser mais legais ou mais autoritários;

- Interessa-se pelos alunos;
- Preocupa-se com seu aprendizado e com seu futuro;

- É motivado por uma vontade intrínseca. $\mathrm{Na}$ visão dos alunos-pacientes, ele não é pago para ensinar;

- É marcado pelo desejo de ensinar;

- É compreensivo frente às dificuldades dos alunos.

No que diz respeito ao seu papel e atuação, à exceção daquilo que foi destacado acima, os sentidos construídos pelos sujeitos a respeito do professor hospitalar se assemelham àqueles atribuídos ao professor da escola de origem. Ele está ali para ensinar, e o ensino é visto como uma transferência de conhecimento daquele que sabe para aquele que não sabe. Há, no entanto, a possibilidade de um diálogo entre professor e aluno através de conversas que se relacionam a assuntos diversos.

O aspecto mais marcante no que diz respeito ao professor hospitalar é a afetividade impressa em sua relação com o aluno-paciente. Esse profissional carrega características atribuídas à imagem ideal do professor da escola de origem.

Junto a isso, há uma idealização do professor hospitalar, que aparece através de algumas expressões utilizadas pelos alunos-pacientes como "professor-anjo", por exemplo. Esse profissional aparece envolto em onipresença e onipotência, na visão do aluno-paciente. Ele sempre estará disponível e poderá ajudar o sujeito em qualquer situação.

A relação professor-aluno é, no mais das vezes, vista como mais próxima. O professor hospitalar é um amigo. Ele se interessa pela situação do aluno-paciente, observa o que se passa com o sujeito e é capaz de compreender sua situação. Porém, ao mesmo tempo, ele 
pode ser entendido como menos exigente, o que nem sempre é visto como algo positivo.

Aprendizagem na escola de origem

- Aprender na escola se relaciona aos conteúdos formais, a um conteúdo moral (saber se comportar) e a um aprendizado sobre os "fatos da vida" (gravidez, por exemplo);

- O docente é quem conduz o aprendizado, e seu saber e interesse são fundamentais para que a aprendizagem ocorra;

- Caso não haja um empenho por parte do aluno, a aprendizagem não irá ocorrer;

- Aprender é adquirir uma certa quantidade de conhecimento passado pelo professor;

- Trabalhos em grupo, discussões em sala e seminários são estratégias de aula valorizadas;

- A escola de origem é um lugar no qual aprender é difícil devido ao grande número de alunos na sala e à bagunça que ocorre.

Como é possível ver, as atividades em grupo são valorizadas. É possível supor que exista essa visão por parte dos sujeitos na medida em que tais atividades corresponderiam a um resgate da palavra pelo estudante e garantiriam maior contato com os colegas. Há aqui, no entanto, uma contradição. Os sujeitos valorizam a aula aberta, com trabalhos em grupo, debates e a possibilidade de o aluno dar sua opinião, ao mesmo tempo em que aparece a percepção de que a aula que garante o aprendizado é aquela na qual temos um professor comandando as ações e utilizando-se da prova como forma de controle.

\section{Aprendizagem na escola hospitalar}

Existe um caráter fundamental que marca essa atividade: o professor hospitalar trabalha com apenas um aluno-paciente. Esse fato traz algumas vantagens:

- O sujeito se sente mais à vontade para fazer perguntas;

- Há maior diálogo com o professor, o que facilita a aprendizagem;

- Menos alunos em sala equivale a menos bagunça, menos distração para o estudante, o que produz um aprendizado maior.

Há, porém, desvantagens inerentes ao caráter particular da aula:

- Os colegas, ausentes na escola hospitalar, auxiliavam a tirar as dúvidas em sala de aula na escola de origem;

- Cresce a seriedade na hora da aula, o que produz tédio nos estudantes;

- A presença de outras pessoas na classe auxiliava o sujeito a avaliar seu próprio ritmo de aprendizagem, o que não acontece na escola hospitalar devido à ausência dos colegas.

Aprender no hospital carrega, também, outras marcas específicas:

- Aprender ao mesmo tempo em que se lida com a doença é um desafio, devido aos enjôos e à apreensão frente à doença e ao tratamento;

- Aprender no hospital se refere aos conteúdos, às relações entre as pessoas, à vida e a um saber médico a respeito da doença;

- Algo negativo em relação à aprendizagem no hospital está ligado ao fato de que ela se refere apenas a uma revisão dos conteúdos já trabalhados na escola de origem. 


\section{Discussão}

Quando chega à escola hospitalar, o sujeito, especialmente no caso dos adolescentes, já acumulou durante um longo tempo uma vivência escolar carregada pelos diversos aspectos que marcam a escola de origem (colegas, aulas, aprendizado, conhecimento, esportes, etc.) e por suas práticas historicamente constituídas. Seu contato com múltiplos professores foi também diverso e intenso. Dessa forma, ao se deparar com uma realidade que desconhece, a da escola hospitalar, acompanhada pela doença e pelo tratamento, o indivíduo recorre aos sentidos já formulados a respeito da escola de origem e de seu professor na tentativa de interpretar tal realidade. No entanto, num movimento dialético, novos elementos são agregados à rede original de sentidos, produzindo nela modificações. Tais elementos atribuem à nova experiência significações diversas, podendo, inclusive, alterar o sentido que o sujeito constituiu a respeito da escola de origem e de seu professor. Há, portanto, um jogo dinâmico entre os sentidos produzidos em relação à escola de origem e aqueles relativos à escola hospitalar.

Vimos que a escola de origem tem como elementos fundamentais de sentido seus aspectos físicos (lousa, pátio, giz, sala), a presença dos colegas e o seu caráter de "lugar para aprender" (este último desvalorizado e tido como "chato", porém necessário). Com isso, no contato inicial com a escola hospitalar, são tais características que os sujeitos irão procurar, numa tentativa de reconhecimento desse lugar como um espaço escolar e da atividade ali realizada como uma atividade escolar, daí o fato de a escola hospitalar aparecer definida através da negação: ela não tem lousa, ela não tem giz, ela não tem sala, ela não tem colegas. No confronto com a realidade hospitalar, o sujeito não reconhece nesse espaço os elementos caracterizadores da escola. Nesse momento, ela não é uma escola.

De fato, o que aparece como um índice identificável de escola é o professor hospitalar. Com o rareamento dos aspectos caracterizadores da escola, no hospital, a escola passa a ser o professor. Num ambiente marcado pela doença e pelo tratamento, reconhece-se a escola na figura do professor. A visão que se tem a respeito dessa figura é interessante. No discurso dos sujeitos, vemos como o processo ideológico, descrito por Freire (1987), que toma o professor como dono do saber, como portador do conhecimento, não é rompido na atuação dentro do hospital. O professor hospitalar ainda é aquele que sabe, aquele que é capaz de ensinar o aluno-paciente, e sua atuação não é vista de modo tão diferente daquela do professor da escola de origem. Entretanto, no mesmo campo de sentido, convivem elementos contraditórios, e o professor hospitalar é também aquele que dialoga, que ouve o sujeito, vivendo com ele uma relação mais horizontal.

Ao falar da escola de origem, os sujeitos se referem ao professor através de uma validação ou de uma reprovação de sua conduta. Os professores podem ser bons ou ruins, legais ou chatos. Esses critérios estão ancorados principalmente no aspecto afetivo, representado pela idéia do interesse. O bom professor se interessa pelo aluno, se preocupa com ele e quer saber se o estudante aprendeu o que foi ensinado. Ele atua mais próximo do aluno, o que traria vantagens para o aprendizado. Tal expressão do afetivo na relação professor-aluno, verificada nessa pesquisa, é similar ao que Tassoni (2006) e Leite (2006) descrevem em um contexto "regular", não hospitalar, no qual a proximidade entre o professor e o aluno é dado marcante. 
${ }^{2} \mathrm{O}$ termo perturbação do sentido não tem respaldo nos autores utilizados como base. No entanto, consideramos que expressa adequadamente a instabilidade e a tensão provocadas, nos sentidos, por novas experiências semelhantes, como, no caso, a escolar, mas com elementos distintos que têm o potencial de alterar elementos estáveis, até porque respaldados pelos significados.
O professor hospitalar, caracterizado desse modo, é carregado pelo aluno-paciente de uma carga afetiva bastante positiva que, em alguns casos, aparece na forma de idealização dessa figura. Dado o fato de que o critério utilizado pelos sujeitos na avaliação do professor hospitalar e do bom professor da escola de origem coincidem, podemos supor que a experiência hospitalar permita uma ressignificação, que aqui chamamos de "perturbação no sentido" ${ }^{2}$, acerca do professor da escola de origem, ou seja, há a possibilidade de que, antes da experiência hospitalar, as zonas de sentido acerca do professor comportem apenas a idéia de dono do saber, dono da palavra, mesmo que nem todos os docentes atuem dessa forma. A passagem pela escola hospitalar permite que a experiência do sujeito com professores menos autoritários seja retomada, reavaliada e ressignificada.

Entretanto, o sentido de professor hospitalar "perturba o sentido" de professor da escola de origem, ao mesmo tempo em que é por ele "perturbado". É por conta disso que o professor hospitalar segue sendo aquele que sabe e tem como tarefa básica ensinar os conteúdos, independentemente de como o faça. O professor hospitalar é devedor dessa idéia na medida em que ela é um elemento caracterizador do espaço escolar que o aluno conhece, ela constrói esse sentido acerca da escola e do professor: o fato de ser dono do saber faz o professor ser professor.

A "perturbação" que ocorre, mesmo agindo nos dois sentidos, trabalha a favor de uma perspectiva crítica em educação, abalando uma concepção mais estável do aluno acerca do professor. Há uma ampliação dessas zonas de sentido que comportam, agora, a idéia do diálogo, da troca e da maior horizontalidade na relação. A experiência na escola do hospital pode ser uma experiência que devolve o sujeito à escola de origem não mais como o aluno recebedor de informações, mas como um educando ativo no processo de construção de sua própria aprendizagem. Podemos dizer que a relação professoraluno é o aspecto da escola mais abalado pela experiência na escola hospitalar tendo, inclusive, influências na relação que o aluno estabelece com os objetos do conhecimento. Leite (2006) mostra como a mediação do docente entre o aluno e o conhecimento comporta uma carga afetiva que constrói, para o bem ou para o mal, a relação do aluno com o saber. A vivência afetiva com o professor hospitalar, ou seja, o vínculo que se estabelece marcado por um caráter positivo, também atua reconstruindo a relação dos sujeitos com determinados conteúdos, daí termos relatos de jovens que afirmam que detestavam matemática ou outra matéria, e que passaram a se interessar mais por tal disciplina depois de estudar no hospital.

A proximidade do professor em relação ao cotidiano hospitalar do aluno-paciente também merece comentários. O professor passa a acompanhar aquilo que se tornou o cotidiano do aluno: a doença e o tratamento. Essa proximidade, valorizada pelos sujeitos, garante uma compreensão, por parte do docente, da realidade do sujeito com câncer. Além disso, as atividades na escola hospitalar ocorrem exatamente nesse cotidiano, "o aluno estuda enquanto se trata", e se reveste de um caráter que não é apenas pedagógico: a aula permite ao aluno esquecer por alguns momentos a sua doença e faz com que ele acredite na possibilidade de continuar suas atividades. Dessa maneira, a ação docente age potencializando o sujeito, na medida em que oferece alternativas de atividade e continuidade escolar que vão além da doença.

No entanto, a figura do professor não basta para garantir o caráter escolar ao espaço hospitalar. Há a necessidade de uma relação entre a vivência hospitalar e aquilo que seria a função da escola de origem na percepção 
desses sujeitos: ensinar e oferecer ao aluno a promessa de uma inserção social futura, a partir de um emprego e uma boa condição de vida. Esse caráter é garantido à escola hospitalar pela sua ligação com a escola de origem, materializada nos contatos feitos regularmente, no programa enviado para ser trabalhado pelo aluno-paciente, portanto, pelo conteúdo ensinado e pelos relatórios feitos pelos profissionais da escola hospitalar acerca do aluno, que servem como uma avaliação para a escola de origem. Sem isso, a escola hospitalar teria seu sentido de escola esvaziado, porque não garantiria a continuidade escolar, o passar de ano, o que, no limite, romperia a promessa de futuro, de validação da experiência escolar através da inserção social, do bom emprego esperado pelos estudantes, promessa que aparece como algo que não se cumpre na fala daqueles sujeitos que já terminaram a escola e que têm de lidar com o mercado de trabalho. Há um distanciamento entre a escola e a realidade do aluno nos seus diversos aspectos, distância essa que é histórica na educação brasileira.

Como mencionamos, o significado da escola de origem está marcado pela sala de aula, porém sua presença não é fundamental como forma de estímulo à aprendizagem formal. A escola hospitalar não é a escola de origem e nem deve pretender sê-la. Não teria porque carregarmos o espaço hospitalar de índices característicos da escola, na medida em que seu sentido de escola está garantido pela ligação, até certo ponto abstrata, com a própria escola de origem. Essa ligação tem um caráter abstrato, porque está ancorada na promessa a que nos referimos, na idéia de continuidade e de futuro, que, aliás, é questão central na vida dos pacientes com câncer. O vínculo com o futuro que a escola hospitalar herda da escola de origem ganha novas significações no espaço hospitalar. Tal idéia de futuro passa a ter um aspecto imediato, a possibilidade de um amanhã que o câncer rapta, já que está relacionado, no imaginário social, à morte, como afirma Sontag (1984).

Montar uma sala de aula, colocar lousa, giz, carteiras, cantina e tocar um sinal para advertir os alunos do momento da aula são coisas inviáveis frente à rotina hospitalar. $\mathrm{O}$ sujeito é, antes de tudo, um paciente no hospital, um paciente-aluno, cujo objetivo primeiro é cuidar de sua saúde, tratar-se. Além disso, tais atitudes agiriam mascarando uma realidade que não se pretende permanente e que não se basta sozinha. É desse modo que, contraditoriamente, a escola no hospital depende da escola de origem, mas liberta-se dela. Assim como os aspectos físicos, outros elementos podem desaparecer ou ser modificados. Dessa forma, o conteúdo, necessário, como vimos, ganha a participação do aluno-paciente que escolhe o que quer estudar, o programa de ensino pode ser adequado, modificado frente às diversas situações (vive-se uma contradição entre o currículo oficial e as necessidades específicas do aluno), a hora da aula respeita o tempo do indivíduo e não o tempo da produção e do trabalho, a cobrança se ameniza e as avaliações perdem espaço. Os critérios para a organização e a condução do trabalho passam a ser outros na escola hospitalar, diferentes, mas não opostos aos da escola de origem. Estudos a respeito desses critérios mencionados são escassos ou inexistentes; no entanto, é importante um olhar pormenorizado para esses diversos aspectos na busca de ampliar a discussão acerca do papel da escola hospitalar e das suas possibilidades de atuação.

O contexto no qual está inserida essa modalidade de ensino produz especificidades que, ao mesmo tempo em que fazem dela dependente da escola de origem para existir, mostram que ela não pode ter sua atuação balizada pela instituição escolar nem se propor a validar as experiências desta a 
partir de sua realidade e de seus critérios. É aqui que promovemos a inversão na idéia inicial de que, devido ao rareamento dos elementos caracterizadores da escola, a escola hospitalar não é uma escola, mas é transformada, de uma negação, em uma afirmação da diferença, da especificidade: a escola hospitalar é uma não-escola.

A escola hospitalar não deve imitar a escola de origem, mas não pode se furtar a ter uma especificidade relacionada ao saber. Como espaço escolar, ela deve ter um saber organizado. Além de um vínculo com o professor-hospitalar e um vínculo com a escola de origem, o conhecimento deve aparecer como elemento fundamental, carregando, inclusive, um caráter de exigência por parte da escola hospitalar. Obviamente, essa exigência não será igual à da escola de origem; é, porém, um conhecimento específico que precisa do programa escolar da escola de origem, mas que o reorganiza, que deve existir e ser formalizado para que a escola hospitalar seja uma escola específica. O conteúdo e o conhecimento possuem uma outra função nesse espaço. A morte aparece pouco na fala dos sujeitos ao longo das entrevistas. No mais das vezes, ela é citada como algo que ocorre com os colegas, trazendo sofrimento para quem está próximo. A possibilidade de sua própria morte é escassa na fala dos sujeitos. Entretanto, é de se supor que tal idéia atravesse a mente desses indivíduos, mesmo que seja representada pelo silêncio, por um não-dito. As entrevistas feitas neste trabalho acabam por mostrar aos jovens participantes as questões da escola, do estudo, do conhecimento, do professor, dos colegas e do cotidiano escolar, afastando-os da presença constante da morte. As aulas no hospital têm o mesmo sentido, preenchendo o aluno com outros assuntos que ocupam o lugar da doença, do tratamento e da morte. A escola pré-ocupa o sujeito, como sugere Cortella (1998), e a escola hospitalar faz isso, trazendo elementos para que ele preencha espaços antes ocupados apenas pelo hospital, pela doença e pela morte.

Quanto a esse aspecto, a função do conhecimento na escola hospitalar é ambígua. Por um lado, o afastamento das questões relativas à morte pode sugerir algo negativo, na medida em que diversos autores, como Kovács (1992), atentam para a importância da expressão e do significado dessas questões por parte do sujeito que está frente à possibilidade da morte. Ao mesmo tempo, a escola e o conhecimento promovem um resgate do mundo do jovem anterior à doença, cuja perda é sentida, como diz Valle (1997), com as vivências da doença e da hospitalização. Há uma tensão entre a necessidade de dar significado à possibilidade da morte e aos sofrimentos da doença e do resgate e da vivência do mundo fora do hospital, representado pela aula e pelo conhecimento.

Falamos anteriormente do aluno no hospital como um paciente-aluno, e, no entanto, referimo-nos a ele durante todo o trabalho como um aluno-paciente. Por que essa diferença? Ainda que exista aqui a percepção do sujeito como alguém que está no hospital primordialmente para se tratar, sendo primeiramente paciente, entendemos que o momento da aula é diferenciado no contexto hospitalar. Mesmo interrompido pelos procedimentos diversos pelos quais o sujeito passa, a aula tem de aparecer como um espaço no qual o indivíduo é arrancado da condição de paciente, na qual ele é colocado sob diversos olhares dentro do hospital, passando a ser alguém ativo, atuante. Concordamos, portanto, com Medeiros e Gabardo (2004) quando vêem o professor hospitalar como alguém responsável pela transformação do sujeito em agente ou, nos termos aqui propostos, de paciente-aluno em aluno-paciente. 
É importante dizer que viemos nos referindo, nesta pesquisa, a uma educação hospitalar que se volta para o trabalho com pacientes oncológicos e que carrega as especificidades características dessa população. Os sentidos acerca do professor hospitalar e da escola, produzidos pelos sujeitos entrevistados, vêm atravessados pelas idéias socialmente atribuídas ao câncer e, não necessariamente, dizem respeito a qualquer outro atendimento escolar hospitalar que lide com uma população diferente. No entanto, as idéias colocadas acerca da relação professor-aluno no contexto hospitalar e da relação entre a escola de origem e a escola hospitalar nos parecem ter uma amplitude grande e se adequam ao contexto geral relativo à educação hospitalar. Fica, de todo modo, a indicação para novas pesquisas que venham a dialogar com tais idéias na busca da construção de um conhecimento cada vez maior sobre esse assunto.

Por fim, a escola hospitalar é, a nosso ver, uma iniciativa importante que se afirma na especificidade de sua prática educativa. Ela se coloca como uma possibilidade de o sujeito se manter vinculado a sua escolarização e a suas perspectivas a respeito do futuro. Na medida em que nela aparece um vínculo afetivo forte do aluno-paciente com o professor hospitalar, a escola hospitalar se constitui em um espaço no qual o conhecimento também pode ser carregado de uma afetividade positiva e ganhar um papel diferenciado. Esse saber mediado pelo professor hospitalar, caso seja considerado relevante, pode ser um elemento potencializador do sujeito, agindo como algo que pode ajudar na relação do alunopaciente com a doença e com o tratamento.

Eduardo Caliendo Marchesan*

Doutorando do programa de Psicologia da Educação e membro do Grupo de Pesquisa em Pensamento e Linguagem (GPPL) na Faculdade de Educação da Universidade Estadual de Campinas (UNICAMP).

Ana Mercês Bahia Bock

Doutora em Psicologia social; professora titular da Pontifícia Universidade Católica de São Paulo. E-mail: anabock@pq.cnpq.br

\section{Antonio Sergio Petrilli}

Doutor em Pediatria e Ciências Aplicadas à Pediatria pela Universidade Federal de São Paulo; professor adjunto da Universidade Federal de São Paulo e superintendente-geral do Grupo de Apoio ao Adolescente e à Criança com Câncer.

E-mail: sergiopetrilli@graacc.org.br

\section{Amalia Neide Covic}

Doutora em Educação pela Pontifícia Universidade Católica de São Paulo; coordenadora do Setor de Pedagogia do Instituto de Oncologia Pediátrica da Universidade Federal de São Paulo.

E-mail: amalia.covic@gmail.com

\section{Eduardo Kanemoto}

Mestre em Literatura e Crítica Literária pela Pontifícia Universidade Católica de São Paulo.

Grupo de Apoio ao Adolescente e à Criança com Câncer

Instituto de Oncologia Pediátrica da Universidade Federal de São Paulo

E-mail: eduardo.kanemoto@gmail.com.

\section{*Endereço para envio de correspondência:}

Rua Diana, 820, ap. 131 - São Paulo - SP - Brasil, CEP: 05019-000

E-mail: ecmarchesan@gmail.com 
Referências
Aguiar, W., \& Ozella, S. (2006). Núcleos de significação como instrumento para a apreensão da constituição dos sentidos. Psicologia: Ciência e Profissão, 1(1), 222-245.

Bessa, L. C. (2000). Conquistando a vida: adolescentes em luta contra o câncer. São Paulo: Summus.

Campos, H. (1980). Serafim: um grande não-livro. In O. Andrade, Obras completas de Oswald de Andrade (Vol. 2). Rio de Janeiro: Civilização Brasileira.

Ceccim, R. B. (1999). Classe hospitalar: encontros da educação e da saúde no ambiente hospitalar. Pátio: Revista Pedagógica, 10(3), 41-47.

Ceccim, R. B., \& Fonseca, E. S. (1999). Atendimento pedagógicoeducacional hospitalar: promoção do desenvolvimento psíquico e cognitivo da criança hospitalizada. Temas de Desenvolvimento, 42(7), 24-36.

Covic, A. N. (2003). Atendimento pedagógico-hospitalar: convalidando uma experiência e sugerindo idéias para a formação de educadores. Dissertação de Mestrado em Educação, Pontifícia Universidade Católica de São Paulo, São Paulo.

Cortella, M. S. (1998). A escola e o conhecimento. São Paulo: Cortez.

Fonseca, E. S. (1999a). Classe hospitalar: ação sistemática na atenção às necessidades pedagógico-educacionais de crianças e adolescentes hospitalizados. Temas de Desenvolvimento, 44(8), 32-37.

Fonseca, E. S. (1999b). A situação brasileira do atendimento pedagógico-educacional hospitalar. Educação e Pesquisa, 25(1), 117-129.

Fonseca, E. S. (2000). Atendimento pedagógico-educacional de bebês especiais no ambiente hospitalar. Temas de Desenvolvimento, 9(49), 9-15.

Fonseca, E. S. (2003). Atendimento escolar no ambiente hospitalar. São Paulo: Memnon.

Fonseca, E. S. (2001). Aspectos da ecologia da classe hospitalar no Brasil. Educação on-line. Recuperado em 11 de dezembro de 2005, de http://www.educacaoonline.pro.br/ aspectosdaecologia.asp? fidartigo $=177$

Freire, P. (1987). Pedagogia do oprimido. Rio de Janeiro: Paz e Terra.

González Rey, F. (2005). Pesquisa qualitativa e subjetividade. São Paulo: Thomson.

Kovács, M. J. (1992). Morte no processo do desenvolvimento humano. A criança e o adolescente diante da morte. In M. J. Kovács (Org.), Morte e desenvolvimento humano (pp. 48-57). São Paulo: Casa do Psicólogo.
Leite, S. A. (2006). Afetividade e práticas pedagógicas. In S. A. Leite (Org.), Afetividade e práticas pedagógicas (pp. 15-45). São Paulo: Casa do Psicólogo.

Medeiros, J. G., \& Gabardo, A. A. (2004). Classe hospitalar: aspectos da relação professor-aluno em sala de aula de um hospital. Interação em Psicologia, 8(1), 67-69.

Ozella, S. (2003). Pesquisar ou construir conhecimento: o ensino da pesquisa na abordagem sócio-histórica. In A. M. Bock (Org.), A perspectiva sócio-histórica na formação em psicologia (pp. 113-131). Petrópolis, RJ: Vozes.

Paula, E. M. (2004). Educação, diversidade e esperança: a práxis pedagógica no contexto da escola hospitalar. Tese de Doutorado em Educação, Universidade Federal da Bahia, Salvador.

Pendley, J. S., Dahlquist, L. M., \& Dreyer, Z. (1997). Body image and psychosocial adjustment in adolescent cancer survivors. Journal of Pediatric Psychology, 22(1), 29-43.

Romanelli, O. O. (1980). História da educação no Brasil (1930/1973). Petrópolis, RJ: Vozes.

Sontag, S. (1984). A doença como metáfora. Rio de Janeiro: Graal.

Tassoni, E. C. (2006). Dimensões afetivas na relação professoraluno. In A. S. Leite (Org.), Afetividade e práticas pedagógicas (pp. 47-74). São Paulo: Casa do Psicólogo.

Valle, E. R. M. (1997). Câncer infantil: compreender e agir. Campinas, SP: Psy.

Vigotski, L. S. (2000). A construção do pensamento e da linguagem. São Paulo: Martins Fontes.

Woodgate, R. L. (2005). A different way of being: Adolescents' experiences with cancer. Cancer Nursing, 28(1), 8-15. 